\title{
Locality constraints in nominal evaluation times
}

\author{
Maura O’Leary*
}

\begin{abstract}
The temporal arguments of VPs and adverbs must be locally coindexed with the nearest time abstraction above them (Percus 2000). In contrast, nouns, which also have time arguments, have been noted to have multiple available evaluation times (Enç 1981), often coinciding with the topic time (e.g. Musan 1995, Tonhauser 2002, Keshet 2008) or utterance time (O’Leary 2017, O’Leary \& Brasoveanu 2018). I argue that we can explain the possible temporal interpretations of nouns in a way that makes their behavior consistent with that of VPs and adverbs by positing an analogous locality constraint and making a simple appeal to quantifier raising. I additionally propose that the need for a locality constraint on the coindexing of temporal arguments extends to all predicates introducing novel referents.
\end{abstract}

Keywords. semantics; tense; nouns; evaluation times; binding

1. Introduction. Nominal property times do not always overlap with the time at which the VP predicate of the same sentence holds (Enç 1981, 1986, 1987; Musan 1995, 1999; Tonhauser 2002, 2006, 2020; Keshet 2008). For instance, in (1), the most likely reading is that the people being discussed were prisoners well after they were babies.

(1) In the 1960s, the prisoners were babies.

(Frazier 2019)

While nominal property times are not always required to overlap the verbal property time, they are still under some constraints. For instance, in (1), the noun 'prisoners' can refer to current (adult) prisoners who were babies in the 1960s or to infants who were incarcerated in the 1960s. While either a "present" or "past" interpretation of 'prisoners' is acceptable, there is a third logical possibility that is notably absent, namely one in which people who will be incarcerated in the future were babies in the 1960s.

In this paper, I propose that the temporal argument of a nominal predicate must be coreferent with the nearest time abstraction scoping over it, despite previous claims that nominal property times are completely independent from the other time variables in a sentence (e.g. Enç 1981). This proposal is represented in the following constraint:

Nominal Input Time Locality Constraint

The time variables acting as input times to nominal predicates which introduce novel referents are bound by the nearest time abstraction.

Therefore, in a sentence like (1), if 'prisoners' scopes below the sentential tense, it will have a temporal argument that is coreferential with the time defined by the tense. If the NP is above the sentential tense in the LF, its temporal argument will be coreferential with the utterance time.

\footnotetext{
* I am very grateful for all of the advice and comments that helped to shape this work. Many people in the UCLA linguistics department deserve recognition, including, but not at all limited to, Jessica Rett, Dylan Bumford, Ethan Poole, Tim Stowell, Jesse Harris, and the entire Semantics Tea reading group. Thanks also go to Judith Tonhauser, Adrian Brasoveanu, Donka Farkas, Pranav Anand, Douglas Ezra Morrison, and three anonymous reviewers. Author: Maura O’Leary, University of California, Los Angeles (mauraoleary@ucla.edu).
} 
The former option will lead to a reading where the state of prisoner-hood overlaps the state of baby-hood, the latter to a reading where prisoner-hood overlaps the utterance time.

Before diving into the locality constraint directly, $\$ 2$ presents some prerequisite information about nominal evaluation times: $\$ 2.1$ covers the basics of nominal lexical aspect and $\$ 2.2$ the limits of nominal lexical aspect and time variable binding constraints outside of the introduction of novel discourse referents. $\S 3$ returns to the main point of locality constraints and discusses similar work done on verbal and adverbial temporal arguments. $\$ 4$ motivates the need for a local binding constraint for the temporal arguments of nominal predicates through data from existential "there" constructions $(\$ 4.2)$ and de dicto readings $(\$ 4.3)$. $\S 5$ presents evidence that a local binding constraint is needed for predicates outside the nominal, verbal, and adverbial domains, leading to the proposal of the generalized constraint in (3).

\section{(3) Temporal Locality Constraint (TLC)}

The time variables acting as input times to any predicates which introduce novel referents are bound by the nearest time abstraction.

2. More about nominal evaluation times. The analysis of nominal evaluation times involves three intertwining facets (O'Leary, forthcoming):

(4) a. Nominal lexical aspect: Nouns naturally separate into three lexical aspect classes, which each interact with their time argument in a distinct way.

b. Syntactic constraints on the binding of time arguments: The time arguments of nominal predicates are coreferent with either the utterance time or a topic time, constrained by a requirement for local binding.

c. Novelty effects: Nominal lexical aspect and binding constraints only apply to nouns in DPs introducing novel entities. In non-novel DPs, the noun behaves more like an overt index, used to identify a previously identified group bearing that property, and does not interact with a time argument.

As this paper only presents argumentation for the second of these, this section briefly introduces the other points, as these two points have, in the past, made the data surrounding nominal evaluation times unclear.

2.1. NOMINAL LEXICAL ASPECT. It has been long established that nominal predicates separate into individual and stage level predicates (Carlson 1977a,b; Musan 1997). Individual level nouns denote properties that hold for the entirety of the individual's existence (e.g. 'human,' 'cat'), while stage nouns describe a temporal chunk, or stage, of the individual's existence. Stage-level nouns can be divided into two further categories, based on temporal behavior (O'Leary 2017, O’Leary \& Brasoveanu 2018).

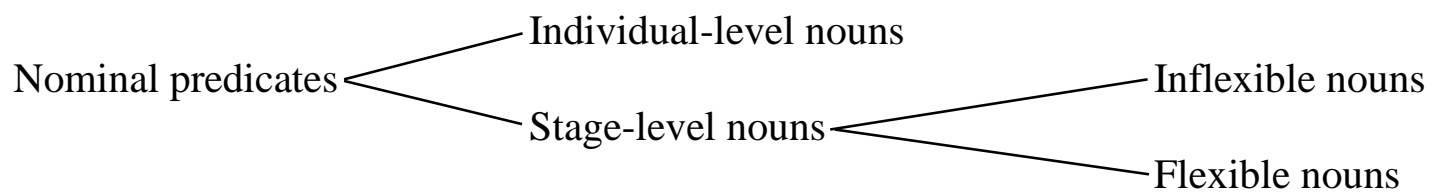

The properties denoted by "inflexible" nouns (which include 'bachelor' and 'teenager') must hold for an interval overlapping their time argument. (This time argument must be coreferent with some time abstraction in the sentence, as will be discussed in $§ 4$.) The properties denoted by "flexible" nouns (for instance, 'fugitive' and 'astronaut') must hold for an interval which either overlaps or precedes the noun's time argument. Because flexible nouns allow a reading where 
the nominal property time completely precedes all other times in the sentence, the sentence in (6) has a reading where 'fugitive' (a flexible noun) means 'former fugitive.' However, the same cannot be done for inflexible nouns, which require the interval over which the nominal property holds to overlap another time in the sentence; therefore (7) does not allow a reading where 'bachelor' (inflexible) is interpreted as 'former bachelor.'

(7) \# A bachelor is married.

flexible

inflexible

The time at which the nominal property denoted by 'fugitive' holds does not overlap any of the times defined by time abstractions in the sentence, however, there is reason to believe that 'fugitive' has a time argument that is coreferent with the utterance time or a topic time; a flexible noun like 'fugitive' has a property time that may overlap or precede its time argument (see O’Leary 2017; O’Leary \& Brasoveanu 2018; O’Leary, forthcoming). I adopt separate terminology for the two distinct temporal references: the input time (the bound time argument) and the property time (the interval at which the property holds). In (6), the property time of the flexible noun 'fugitive' precedes its input time (which, in a present tense sentence, will either be the utterance time or a topic time that is equivalent to the utterance time); note that a property time for 'fugitive' which overlaps its input time is allowed, but leads to a contradictory state of affairs. In (7), the property time of the inflexible noun 'bachelor' obligatorily overlaps its input time (again, the utterance time), leading to an unavoidable contradiction.

To avoid the complexities of nominal lexical aspect, this paper largely focuses on inflexible nouns going forward, as those are the only nominal predicates for which the time argument is guaranteed to be within the interval over which the property holds. While the generalizations I present in this paper hold for all nouns, the effects of nominal lexical aspect make the patterns harder to observe for some nouns than others. Therefore, readers should be aware that if they replace the nouns used in example sentences with other nominal predicates, the results might not be as immediately clear.

Throughout this paper, I use the terminology of "input times" to stand for the time argument of the nominal predicate, in order to remain compatible with work on nominal lexical aspect.

2.2. NovelTy. It is likewise important to know that the information presented in $\$ 2.1$ and the rest of this paper only applies to predicates introducing novel referents; predicates referring to discourse-established referents do not follow the same patterns (O'Leary, forthcoming). (8), like (7) above, could only be true in an illogical situation wherein referents are simultaneously married and unmarried. However, a similar proposition discussing non-novel referents, found at the end of (9), is perfectly acceptable.

(8) \# Some bachelors are married.

(9) I attended college with many bachelors. I just saw some of them again, and two bachelors are married.

In (9), the second use of the predicate 'bachelors' refers to individuals that were bachelors at the time at which the speaker attended college, rather than the utterance time, at which they are married. We can see the same effects even in sentences where the alternative outcome (in which the nominal property time overlaps the utterance/topic time) would not lead to a direct contradiction, as it does in (9): the only available reading of (10) is one in which the subject of the second sentence was 20 years old in the 90 s, rather than last year or at the utterance time. 
(10) When I studied abroad in the 90's, I only made two friends - a 20-year-old and a 32-yearold. Last year, the 20-year-old came to visit me in California.

To avoid these effects, in this paper, I assume that any predicate under discussion is entirely novel to the conversation.

3. Verbal and adverbial evaluation times. In this work, I propose that the time arguments of nominal predicates are locally bound. This is not the first claim of its type; Percus (2000) claims that verb phrase and adverbial input times are locally bound by the nearest time abstraction. ${ }^{1}$

\section{(11) Generalization X}

The time and world variables acting as inputs to a verb phrase are bound by the nearest time and world abstractions.

$(\approx$ Percus 2000:201)

\section{(12) Generalization Y}

The time and world variables acting as inputs to an adverb are bound by the nearest time and world abstractions.

$(\approx$ Percus 2000:204)

(13) and $(14)^{2}$ are provided below as illustrations of the claims that Generalizations $X$ and $\mathrm{Y}$, respectively, make about time variables. In both examples, there are two time abstractions, one provided by the utterance time $\left(t_{0}\right)$ and one provided by the sentential tense $\left(t^{\prime}\right)$. I will refer to these as the Utterance Time (UT) and the Matrix Clause Time (MCT), where the latter is roughly equivalent to the topic time.

In (13) and (14), in line with Percus' Generalizations $X$ and $Y$, the time at which the underlined content holds must be coreferent with the nearer of the two time abstractions - the MCT $\left(t^{\prime}\right)$. Namely, in (13), the input time to the VP 'be in kindergarten' must be coreferent with the time defined by the sentential tense $\left(\mathrm{MCT} / t^{\prime} \approx 1980\right)$. There is no reading of $(13)$ in which the professors are in kindergarten now $\left(t_{0}\right)$ and not in $1980\left(t^{\prime}\right)$ - a reading that should be acceptable if the input time of 'be in kindergarten' were allowed to be coreferent with the UT $\left(t_{0}\right)$. Likewise, in (14), the input time of the adverb 'obligatorily' must be coreferent with the MCT $(t$ ' $\approx$ the 70 's); (14) has no reading in which the professors are obliged to wear ties now $\left(t_{0}\right)$, but not in the 70 's $\left(t^{\prime}\right)$.

(13) $\lambda \mathrm{t}_{0} .\left[\mathrm{PAST}_{\mathrm{t} 0}\left[\lambda \mathrm{t}^{\prime}\right.\right.$. In 1980, my syntax professor was in kindergarten.]]

(14) $\lambda t_{0} .\left[\mathrm{PAST}_{\mathrm{t} 0}[\lambda \mathrm{t}\right.$ '. In the 70's, my professors obligatorily wore ties.]]

\footnotetext{
${ }^{1}$ Percus' generalizations originally read "The situation pronoun that a verb/adverbial quantifier selects for must be coindexed with the nearest $\lambda$ above it." I have rephrased them using different terminology for the following reasons:

- Percus uses "situations" to mean temporally located "parts of worlds" (2000:185); Keshet (2008) specifically shows that these generalizations hold for worlds and times. I separate his situation pronouns into independent world and time pronouns, for two reasons: (i) in this paper, I only intend to make claims about times, and (ii) worlds and times do not seem to reliably come in pairs when considering nominal predicates (O'Leary, forthcoming).

- I use the term "inputs" to be compatible with nominal lexical aspect, as discussed in §2.1.

- I use "verb phrase" rather than "verb" to account for the fact that Percus uses this generalization to explain any type of predicate acting as the main predicate of the sentence (e.g. 'be a semanticist,' 'be Canadian'), rather than just lexical verbs.

- I change "co-indexing" to "binding," as Percus clarifies that "nearest" means "the lowest $\lambda$ that ccommands the pronoun" (2000:201) and describes the generalizations as "binding principles" (2000:205).

${ }^{2}$ Based on examples from Keshet $(2008: 119,124)$.
} 
The input times for both VPs and adverbs must be coreferent with the nearest time abstraction. Readings where their input times are coreferent with any other time abstraction are not felicitous.

4. Nominal evaluation times. If VPs and adverbs must be evaluated at the time introduced by the nearest time abstraction, then it stands to reason that the same may be true for other predicates. In this section, I consider the possible input times for nominal predicates.

In a single clause utterance, bearing only one sentential tense, there will always be two time abstractions with which a given predicate's input time could potentially be coreferent - the UT and the MCT. As we saw in $\S 3$, the input times to VPs and adverbs must be bound by the MCT, as it is the nearest c-commanding time abstraction. Nominal predicates' input times, on the other hand, can be coreferent with either of the time abstractions (O'Leary 2017, O'Leary \& Brasoveanu 2018):

(15) $\lambda \mathrm{t}_{0} . \mathrm{PAST}_{\mathrm{t} 0}\left[\lambda \mathrm{t}^{\prime}\right.$. Four years ago, Melissa met a 10-year-old. $]$

a. Input time $=\operatorname{MCT}\left(t^{\prime}\right) \rightarrow 10$ years old at the time of meeting

b. Input time $=\mathrm{UT}\left(t_{0}\right) \rightarrow 10$ years old at the utterance time

In reading (a), the input time of the nominal predicate ' 10 -year-old' is coreferential with the MCT, producing a meaning in which the child was 10 years old at the time at which Melissa met them. Given that four years have passed, we can assume that the person she met would be around 14 years old at the time (15) is uttered.

In reading (b), the input time of ' 10 -year-old' is coreferential with the utterance time (UT). Reading (b) describes a scenario in which person Melissa met is 10 years old at the time (15) is uttered, and, therefore, would have been roughly six years old at the time of meeting.

It is worth noting that no other readings are available-coreference is required. There is no available reading where the person Melissa met was not 10 years old at a time overlapping either the MCT or the UT. The other logical possibilities - that they were 10 years old at a time (exclusively) prior to the meeting time, between the meeting time and the utterance time, or after the utterance time - are excluded (O'Leary 2017, O’Leary \& Brasoveanu 2018).

4.1. COMPATIBILITY WITH A LOCALITY CONSTRAINT. I propose that the input times of nominals, like those of VPs and adverbs, are subject to a locality constraint, requiring coreference with the nearest c-commanding time abstraction: ${ }^{3}$

\footnotetext{
${ }^{3}$ Keshet (2008) proposes the similar Generalization Z: “The situation pronoun selected for by a noun in a weak NP must be coindexed with the nearest $\lambda$ above it" (2008:126). As mentioned in a previous footnote, there is reason to believe that situation pronouns, in the sense used in this generalization (meaning world-time pairs), cannot account for the behavior of nominal predicates (see O'Leary, forthcoming). Furthermore, Generalization Z only applies to nouns in "weak NPs," referring to NP complements of Milsark's (1977) "strong" and "weak" determiners. However, the same binding requirements described in this paper apply to NPs under "strong" determiners. For instance, the second sentence in (i) is contradictory because the property time of 'bachelors' overlaps that of 'married'-I maintain that this because the input time of 'bachelors' is coreferent with one of the sentence's time abstractions, even though it occurs under the strong determiner "the."

(i) There are lots of happy people in this world. \#The happy bachelors are married.

Readers are invited to repeat the de dicto tests of $\S 4.3$ with data like (i) as evidence against long-distance binding of nominal input times for nouns under strong determiners, or to see O'Leary (forthcoming) for further discussion of the differences between Generalization $\mathrm{Z}$ and the proposals made here. As these differences are based largely on an appeal to novelty, as referenced in $\$ 2.2$, they are outside the scope of this paper.
} 
The time variables acting as input times to nominal predicates which introduce novel referents are bound by the nearest time abstraction.

I propose that the ambiguity exemplified in (15) can be accounted for by an appeal to quantifier raising $(\mathrm{QR})$. Nominal content in an argument $\mathrm{DP}$ can be moved via $\mathrm{QR}$, and this movement has the potential to change which time abstraction is "nearest" to the predicate. To adopt the Nominal Input Time Locality Constraint, we can appeal to the position of the nominal predicate in the LF to derive the ambiguity between UT and MCT coreference in nominal input times: nouns that scope below the sentential tense will be coreferent with the MCT, and nouns that scope above the sentential tense will be coreferent with the UT. (17) demonstrates what this theory would look like for a single clause utterance (square arrows illustrate binding):

(17) Juan met a teenager.

a. $\quad$ Input time $=\operatorname{MCT}\left(t^{\prime}\right) \rightarrow$ teenager at the time of meeting

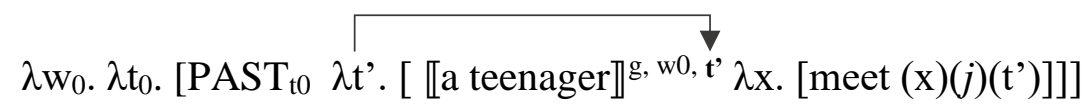

b. $\quad$ Input time $=\mathrm{UT}\left(t_{0}\right) \rightarrow$ teenager at the utterance time

Allowed under the Nominal Input Time Locality Constraint:

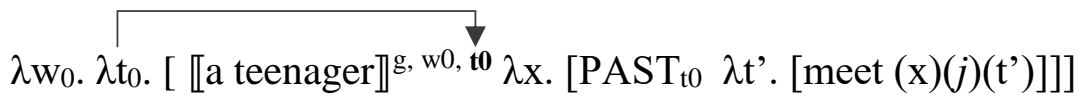

Not allowed under the Nominal Input Time Locality Constraint:

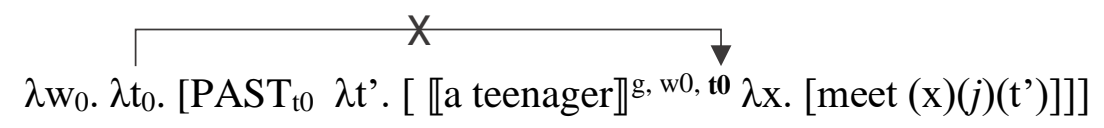

In reading (a), the person Juan met was a teenager when he met them, but need not be a teenager at the time (17) is uttered. In order to abide by the proposed Nominal Input Time Locality Constraint, the LF for such a reading merely needs the DP 'a teenager' to remain below time abstraction defined by the sentential tense.

In reading (b), the person Juan met is a teenager at the time (17) is uttered, but wasn't necessarily a teenager when he met them. In order for the LF for this reading to abide by the Nominal Input Time Locality Constraint, 'a teenager' must have moved above the sentential tense. For any LF in which 'a teenager' sits below the sentential tense, the Nominal Input Time Locality Constraint would rule out coreference between the UT $\left(t_{0}\right)$ and input time of 'teenager.'

The example above shows that the Nominal Input Time Locality Constraint is compatible with the data we have seen so far. The proposed parallelism between VPs, adverbs, and nouns is also appealing. Still, a need for this constraint against the long distance binding of nominal input times must be given. The following subsections demonstrate such a need.

4.2. EVIDENCE FROM EXISTENTIAL “THERE” CONSTRUCTIONS. If long distance binding of nominal input times is barred, then we should expect that if we know the location of the nominal predicate in the LF, the input time will be predictable. A good start would be a construction known to block raising, requiring the DP to remain in situ. 
The post-copular DP of an existential "there" construction cannot undergo QR and must be interpreted in situ (Heim 1987). ${ }^{4}$ Since the DP cannot raise, neither will the nominal complement, forcing it to be interpreted below the sentential tense. Thus, the Nominal Input Time Locality Constraint predicts that the input time of a noun within the post-copular DP of an existential "there" construction must be coreferent with the MCT. Unlike the examples above, there should be no ambiguity regarding nominal input times; a UT input should be strictly ruled out, as it would require long distance binding into the in situ NP.

In (18), the only available reading is one in which the noun 'professor' holds of the subject at the same time as the property of being 'in kindergarten.' The other relevant reading, in which the property of being a professor holds at the UT, well after the person under discussion was in kindergarten, is unavailable, despite being a significantly more plausible situation. An MCT input time is available to the noun in the post-copular DP, while a UT input time is not (Musan 1995, 1999; Keshet 2008).

(18) There was a professor in kindergarten in the 80s.

a. $\quad \checkmark \quad$ Input time $=\operatorname{MCT}\left(t^{\prime}\right) \rightarrow$ professor at the time of being in kindergarten

They were a professor when they were in kindergarten. $\lambda \mathrm{w}_{0} . \lambda \mathrm{t}_{0} .\left[\right.$ PAST $_{\mathrm{t} 0} \lambda \mathrm{t}^{\prime}$. [ there be [a professor $\rrbracket^{\mathrm{g}, \mathrm{w} 0, \mathrm{t}^{\prime}}$ in kindergarten in the $\left.\left.80 \mathrm{~s}\right]\right]$

b. $\quad \# \quad$ Input time $=\mathrm{UT}\left(t_{0}\right) \rightarrow$ professor at the utterance time They were a professor after they were in kindergarten.

LF prohibited based on raising:

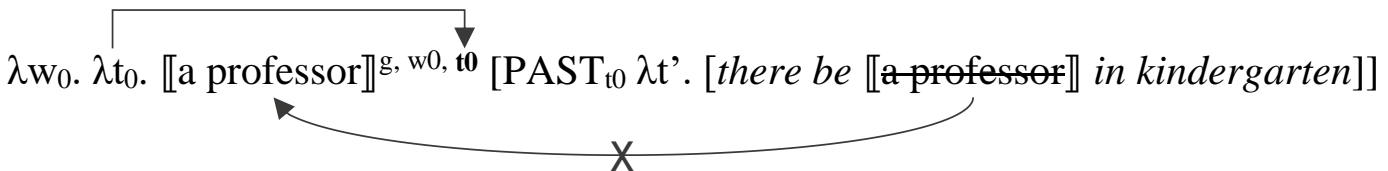

LF prohibited based on the Nominal Input Time Locality Constraint: $\lambda \mathrm{w}_{0} . \lambda \mathrm{t}_{0} .\left[\begin{array}{lll}\mathrm{PAST}_{\mathrm{t} 0} & \left.\lambda \mathrm{t}^{\prime} \text {. [ there be [a professor } \rrbracket^{\mathrm{g}, \mathrm{w} 0, \mathbf{t}^{\mathrm{t}}} \text { in kindergarten in the } 80 \mathrm{~s}\right]\end{array}\right]$

There are two ways to arrive at an LF for the unavailable reading, in which the UT binds the nominal input time of 'professor'-both are ruled out if we accept the Nominal Input Time Locality Constraint. The first option is prohibited based on the restriction on raising (Heim 1987). If the post-copular DP were able to raise above the sentential tense, the locality constraint would be obeyed; however, the raising itself is disallowed. Assuming that the rules around raising are obeyed, the second option would necessitate long-distance binding. To rule out this reading, we need the locality constraint.

4.3. EVIDENCE FROM DE DICTO READINGS. The location of a nominal predicate is also predictable if it must be interpreted below an attitude verb, as in a de dicto reading. However, to discuss sentences with embedded clauses, we must introduce a time variable associated with the embedded tense: the embedded clause time (ECT). Given freedom of movement, a nominal which originates in an embedded clause can use any of the three time variables as an input time: the UT, the

\footnotetext{
${ }^{4}$ Poole (2017) claims that these DPs can raise, but must undergo syntactic reconstruction. For the purposes of this paper, these two theories achieve the same result, which is that the NP is interpreted in situ.
} 
MCT, or the ECT. ${ }^{5}$ Based on the location of the nominal within the LF, the input time is predictable; the following graphic shows the various positions in which a nominal may be interpreted relative to the attitude verb, tenses, and time/world abstractions:

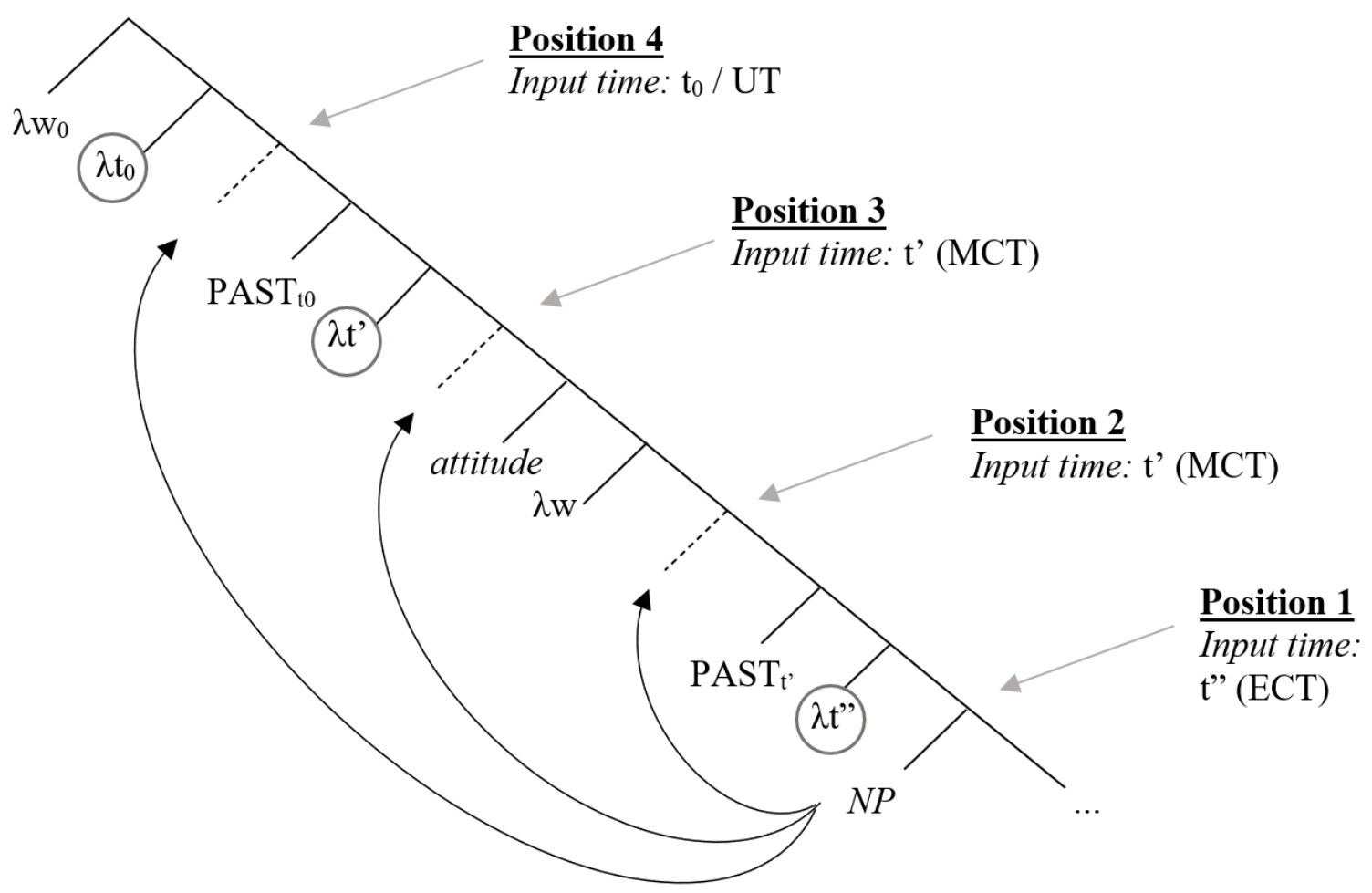

Using a de dicto reading, we can force the NP to be interpreted below the attitude verb, and therefore in one of the two lowest positions shown in (19), "Position 1" or "Position 2," which differ only in their relation to the embedded tense. "Position 1" occurs below the embedded tense, and is predicted by the Nominal Input Time Locality Constraint to require an ECT input time. "Position 2" occurs above the embedded tense but below the attitude verb and is required by the locality constraint to get an MCT input time, as the matrix tense provides the nearest ccommanding time abstraction. There is no position below the attitude verb for which the UT is the nearest time abstraction, so the Nominal Input Time locality Constraint predicts that a UT input time should not be available to a nominal that is interpreted below the attitude verb, as in a de dicto reading. Put another way, if long-distancing binding of input times were available, a UT input time paired with a de dicto reading would be available. A lack of such a reading (de dicto + UT) supports the need for an input time locality constraint.

(20) provides a context and two sentences. In both sentences, the NP in the embedded subject has a UT input time. In (a), the UT input time is paired with a de dicto reading (predicted to be unacceptable by the Nominal Input Time Locality Constraint). In (b), it is paired with a de re reading (predicted to be acceptable).

As these are difficult judgments, the table following (20) provides a summary of the temporal information from (20)'s context. Note that de dicto and de re here refer to the source of the

\footnotetext{
${ }^{5}$ And even a fourth time variable: the time that the matrix subject believes it to be at the time of saying, believing, etc. (equivalent to MCT if they are not mistaken). For the purpose of simplification, I here make the assumption that the matrix subject is not mistaken about what time it is.
} 
information about the embedded subject's age. In the UT + de dicto reading, we are basing the person's age off of Josiah's beliefs about what their age is at the time of the utterance. In the UT + de re reading, we are basing the reported age off of their age in the actual world at the time of the utterance.

Context:

In 2001, Josiah was scared by someone creeping up on him in a parking lot. Although he never saw their face, he saw that the person was very short, so Josiah assumed it was a young child, perhaps 5 or 6 years old. Josiah told me about this event in 2011, ten years after it happened. By now, 20 years after the event, Josiah thinks that the person who scared him is in their 20s. However, we happen to know that the person who scared him was actually Thomas, a very short old man who is now 85 years old.

a. UT + de dicto: \# In 2011, Josiah told me that a 20-something scared him in 2001.

b. UT + de re: $\quad \checkmark$ In 2011, Josiah told me that an 85-year-old scared him in 2001.

\begin{tabular}{llll} 
& ECT & MCT & UT \\
\hline Year & 2001 & 2011 & 2021 \\
\hline Event & scaring & telling & now \\
Actual age & 65 & 75 & $\mathbf{8 5}$ \\
$\begin{array}{l}\text { Josiah's belief about } \\
\text { their age }\end{array}$ & child & teen & $\mathbf{2 0 s}$ \\
\hline
\end{tabular}

Table 1. Timeline of information from the context in (20)

The unacceptability of (20a) provides further evidence that long distance binding of time variables is not possible and that there is need for the Nominal Input Time Locality Constraint. No location in the LF under the attitude verb allows a UT input time, as predicted by the locality constraint. (21) provides the two possible LFs, with the nominals occurring in "Position 1" and "Position 2" from (19), as a visual representation of the long distance binding that is ruled out.

a. Below the embedded tense:

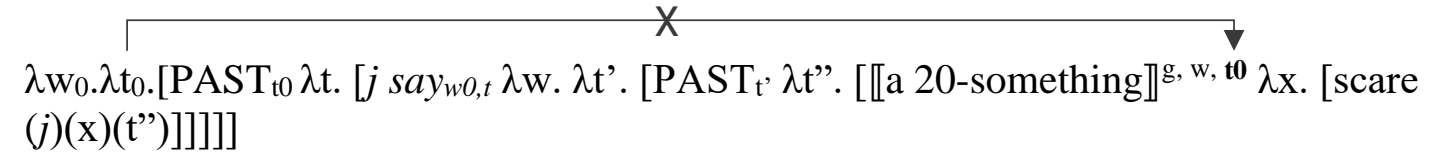

b. Above the embedded tense:

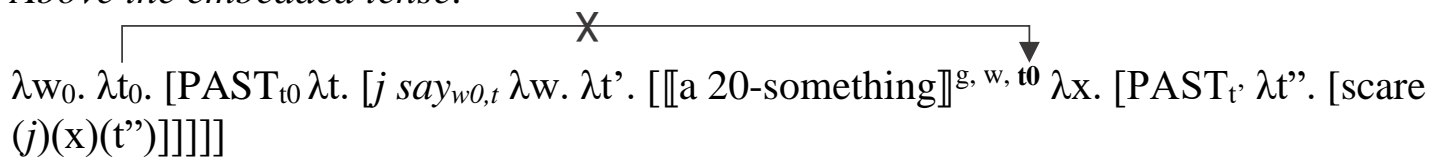

Both existential "there" constructions and de dicto readings provide evidence that long distance binding of nominal input times is ruled out, just as long distance binding of VP and adverbial input times are ruled out, supporting the need for a locality constraint.

5. Other predicates. If the input times to verb phrases, adverbs, and nouns are all subject to locality constraints, what about other predicates and predicative phrases, like adjectives, prepositional phrases, participles, and relative clauses? This section considers whether the locality constraints on input times should be applied to all predicates. 
Adjectives, prepositional phrases, participle phrases, and relative clauses can be used either as the main predicate of a clause, as in (22), or as adnominal modifiers, as in (23).

(22) The basket is $\{$ red/in the cupboard/made in Italy/what I always wanted $\}$.

(23) a. The red basket costs $\$ 20$.

b. The basket $\{$ in the cupboard/made in Italy/that I always wanted $\}$ costs $\$ 20$.

The instances in (22) are already assumed to be subject to a locality constraint; as described above, Percus' Generalization X covers not only verbs, but any predicate acting as the main predicate of the clause.

The uses in (23) are also claimed to be subject to a locality constraint - Ogihara (2003) claims that adnominal modifiers are interpreted relative to the nearest sentential tense. If the input times of these predicates must be locally bound when they are acting as adnominal modifiers, then we should expect them to show the same behavior as nouns they modify. Since DPs move as a whole, we would expect that any predicate within the DP should have the same "nearest" time abstraction as the noun it modifies and therefore the same input time. And indeed, Keshet (2008) notes that:

\section{(24) Intersective Predicate Generalization ${ }^{6}$}

Two predicates combined via Predicate Modification may not have different input times or worlds from one another.

The sentences below demonstrate that a noun and its modifiers must have the same input times. In each, 'bachelor' is paired with a modifier that either asserts or presupposes the property of being married. As these properties cannot logically hold at the same time, the resulting sentences are contradictory.

(25) (Intersective) Adjective + noun:

(26) Prepositional phrase + noun:

(27) Participle + noun: ${ }^{7}$

(28) Relative clause + noun: ${ }^{8}$
\# A married bachelor is here.

\# A bachelor with his wife is here.

\# A bachelor kissing his wife is here.

\# A bachelor who is married is here.

These data are explained either by combining (i) Ogihara's (2003) claim about the relationship between adnominal modifiers and the Nominal Input Time Locality Constraint, illustrated in (29), or (ii) Keshet's (2008) Intersective Predicate Generalization and the Nominal Input Time Locality Constraint, depicted in (30).

\footnotetext{
${ }^{6}$ Keshet's original reads: "Two predicates combined via Predicate Modification may not be evaluated at different times or worlds from one another." I have again used "input times" in an effort for the theory to be compatible with nominal lexical aspect.

${ }^{7}$ See also Kusumoto (1999).

${ }^{8}$ Relative clauses, which contain tense operators, have a lot of interesting effects once you leave the present tense. All of them abide by the locality constraint proposed here; see Abusch (1988).
} 
(29)

Ogihara (2003)

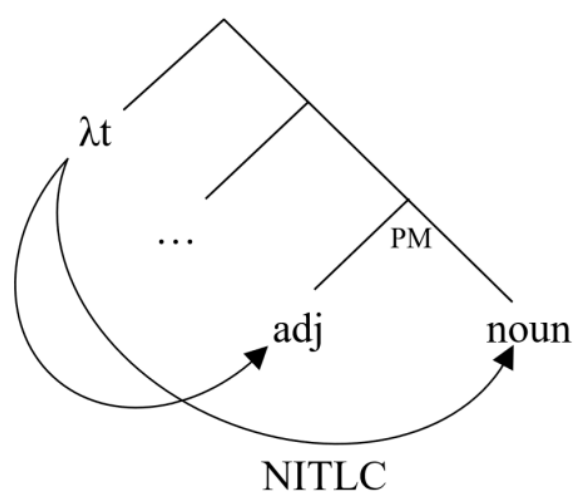

(30)

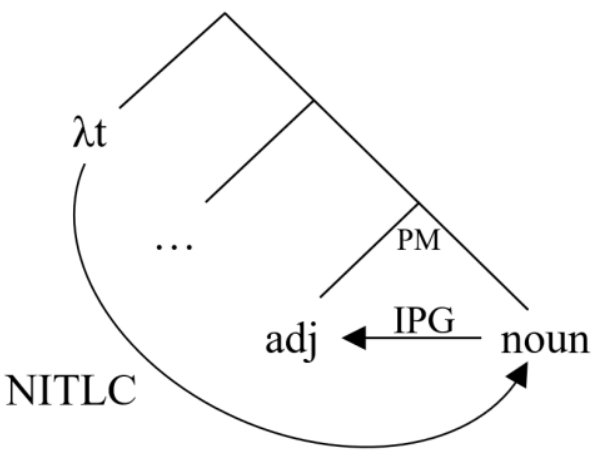

The input times for verbs, adverbs, nouns, adjectives, prepositional phrases, participle phrases, and relative clauses are all locally bound by the nearest c-commanding time abstraction, as currently accounted for collectively by Percus' (2000) Generalization X for VPs and Generalization Y for adverbs, the Nominal Input Time Locality Constraint, Ogihara's (2003) description of adnominal modifiers, and Keshet's (2008) Intersective Predicate Generalization. I propose the following generalized locality constraint, which subsumes the other five claims:

\section{(31) Temporal Locality Constraint (TLC)}

The time variables acting as input times to any predicates which introduce novel referents are bound by the nearest time abstraction.

The generalized Temporal Locality Constraint accounts for every predicate, whether it is within an argument DP, as depicted in (32), or acting as the main predicate of the sentence, as in (33):

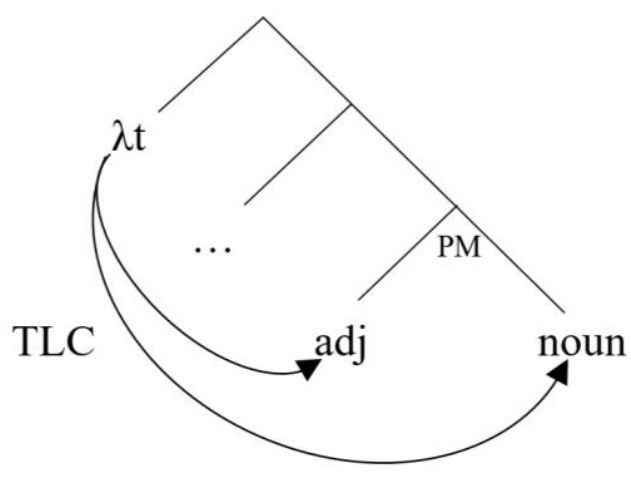




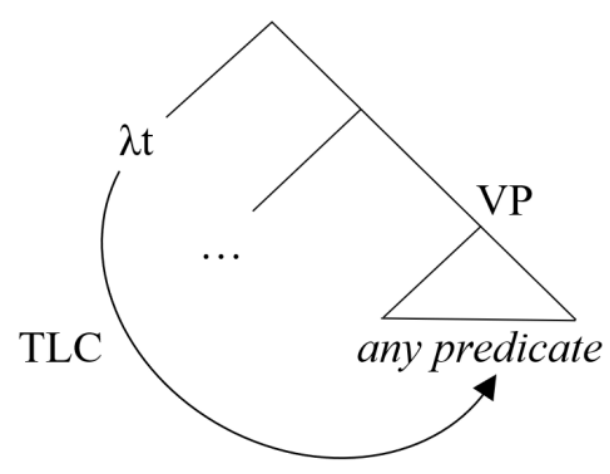

6. Conclusion. Previous works have established that the input times of many predicates are bound by the nearest time abstraction (e.g. Percus 2000, Ogihara 2003, Keshet 2008). Here, I show that nominal input times are also locally bound, and that any temporal ambiguity is easily accounted for by an appeal to quantifier raising. Support for the claim that nominal input times are locally bound comes from existential "there" constructions and de dicto readings - when the noun's location in the LF is predictable, the noun's input time is also predictable.

Given the evidence for local binding constraints on the input times of verbs, adverbs, nouns, adjectives, prepositional phrases, participle phrases, and relative clauses, I propose that the input times of all predicates are bound by the nearest time abstraction, summarized here in a generalized locality constraint:

\section{(31) Temporal Locality Constraint (TLC)}

The time variables acting as input times to any predicates which introduce novel referents are bound by the nearest time abstraction.

Time variables associated with tenses have been considered to be pronominal (Partee 1973). We have seen here that the input times of novel predicates additionally seem to exhibit anaphoric behavior, as they must be coindexed with the nearest time abstraction above them.

\section{References}

Abusch, Dorit. 1988. Sequence of tense, intensionality and scope. West Coast Conference on Formal Linguistics (WCCFL) 7. 1-14.

Carlson, Gregory N. 1977a. Reference to kinds in English. Amherst, MA: University of Massachusetts dissertation.

Carlson, Gregory N. 1977b. A unified analysis of the English bare plural. Linguistics and Philosophy 1(3). 413-457.

Enç, Murvet. 1981. Tense without scope: An analysis of nouns as indexicals. Madison, WI: University of Wisconsin dissertation.

Enç, Murvet. 1986. Towards a referential analysis of temporal expressions. Linguistics and Philosophy 9(4). 405-426. https://www.jstor.org/stable/25001253.

Enç, Murvet. 1987. Anchoring conditions for tense. Linguistic inquiry 18(4). 633-657. https://www.jstor.org/stable/4178564.

Frazier, Lyn. 2019. Topic situations and domain restriction. UCLA Linguistics Colloquium Series.

Heim, Irene. 1987. Where does the definiteness restriction apply? Evidence from the definiteness of variables. In Eric Reuland \& Alice G. B. ter Meulen (eds.), The representation of (in)defi- 
niteness, 21-42. Cambridge, MA: The MIT Press.

Keshet, Ezra R. 2008. Good intensions: Paving two roads to a theory of the de relde dicto distinction. Cambridge, MA: MIT dissertation.

Kusumoto, Kiyomi. 1999. Tense in embedded contexts. Amherst, MA: University of Massachusetts dissertation.

Milsark, Gary. 1977. Towards the explanation of certain peculiarities of existential sentences in English. Linguistic Analysis 3. 1-29.

Musan, Renate I. 1995. On the temporal interpretation of noun phrases. Cambridge, MA: MIT dissertation.

Musan, Renate. 1997. Tense, predicates, and lifetime effects. Natural Language Semantics 5(3). 271-301.

Musan, Renate. 1999. Temporal interpretation and information-status of noun phrases. Linguistics and Philosophy 22(6). 621-661. https://www.jstor.org/stable/25001763.

Ogihara, Toshiyuki. 2003. A scope theory of tense and adnominal modifiers. In Shuji Chiba et al. (eds.), Empirical and theoretical investigations into language. Tokyo: Kaitakusho.

O'Leary, Maura. 2017. Constraints on the evaluation times of noun phrases. Workshop in General Linguistics (WIGL) 14. 47-58.

O'Leary, Maura. forthcoming. The evaluation times of nominal predicates. Los Angeles, CA: University of California dissertation.

O’Leary, Maura \& Adrian Brasoveanu. 2018. The lexical temporal properties of nominal predicates. California Universities Semantics and Pragmatics (CUSP) 11.

Partee, Barbara H. 1973. Some structural analogies between tenses and pronouns in English. The Journal of Philosophy 70(18). 601-609. https://doi.org/10.2307/2025024.

Percus, Orin. 2000. Constraints on some other variables in syntax. Natural Language Semantics 8(3). 173-229. https://doi.org/10.1023/A:1011298526791.

Poole, Ethan. 2017. Movement and the semantic type of traces. Amherst, MA: University of Massachusetts dissertation. https://scholarworks.umass.edu/dissertations_2/1119.

Tonhauser, Judith. 2002. A dynamic semantic account of the temporal interpretation of noun phrases. Semantics and Linguistic Theory (SALT) 12. 286-305.

Tonhauser, Judith. 2006. The temporal semantics of noun phrases: Evidence from Guaraní. Stanford, CA: Stanford University dissertation.

Tonhauser, Judith. 2020. Temporal properties of noun phrases. In Daniel Gutzmann, Lisa Matthewson, Cecile Meier, Hotze Rullmann \& Thomas E. Zimmermann (eds.), The Wiley Blackwell companion to semantics, 1-25. Online: Wiley. https://doi.org/10.1002/9781118788516.sem126. 